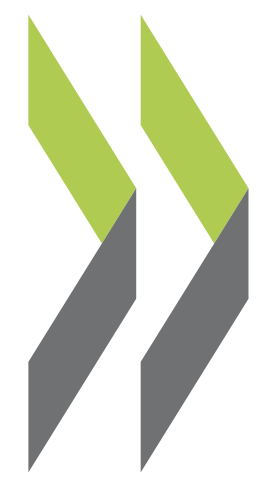

CELE Exchange, Centre for Effective Learning Environments $2011 / 02$

\title{
Making Visionary Design Work at Policy Level and in Practice
}

\section{Frauke Burgdorff}

https://dx.doi.org/10.1787/5kgdzvmtpj8r-en 


\section{Making visionary design work at policy level and} in practice

By Frauke Burgdorff, Montag Stiftung Urbane Räume gAG, Germany
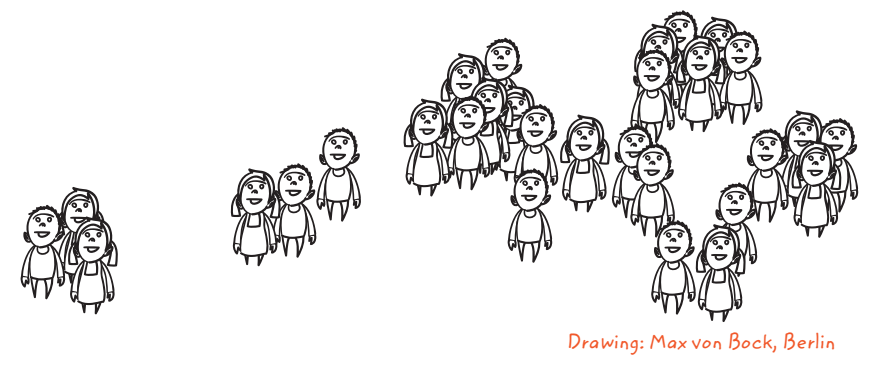

(Translation from German into English: Karoline Brombach)

Good architecture responds to contemporary challenges, irrespective of fashionable trends, and is characterised by rigorous building processes. Office buildings, housing, stadiums and theatres offer outstanding examples of this principle. But do school buildings figure among them? Happily, in Germany they do, although they are still too rare. This article focuses on school building processes and raises the following questions: what sort of challenges will we meet in the future? Will a culture of planning be sufficient to foster the emergence of modern and tailor-made learning environments?

\section{CONTEMPORARY CHALLENGES FACING GERMAN SCHOOL DESIGN}

During the coming years, whenever the interests of pedagogy, building construction and urban development overlap, schools will be confronted with major challenges.

Already in today's world, knowledge is no longer imparted in a standardised manner, hence learning and teaching have to be organised differently. School buildings have to allow for a multitude of learning methods, from individual study to learning in groups of varying sizes; from same-age to mixed-age classes. Not only has the rigid spatial principle of "hallway and classrooms" become obsolete, but schools need to offer an ever-wider ronge of learning opportunities.

In future, pupils and teachers will spend more time in educational facilities. Currently, a child who attends school full time and completes higher secondary education spends up to 20000 hours of his or her life in school. This is about $60 \%$ more time than students who are enrolled in a traditional halfday school. This means that, in effect, school buildings become a second home to learners.

Many school buildings in Germany were designed to operate for half of the day: currently the school day generally ends at midday and students go home for lunch. The premises therefore lack a proper cafeteria as well as multifunctional spaces for individual study or small group learning. Therefore, if schools are to offer a full array of activities including quiet study periods, recreation, sports and leisure, they will need to be adopted to fullotime use.

Teachers are also affected changes that are taking place. They need quality ploces and spaces where they can work undisturbed, i.e. optimal conditions where they can prepare their core activity, which is initiating fruitful and stimulating learning processes. Quality places also include areas where teaching staff can consult with others who also are engaged in the process of learning. 
Schools are regaining importance as neighbourhood centres, i.e. public meeting places and facilities where the community can develop specific interests. Schools can either be part of a network of educational institutions or serve as a venue for diverse learning opportunities. Furthermore, school authorities can decide whether everything is to be provided on site or whether they will develop a network of facilities within the neighbourhood. These decisions have a major impact on the school's architecture and how it is run.

Finally, many German schools are having to adapt to both growth and decline: those concerned are being confronted simultaneously with declining numbers of pupils, growing demands on floor space due to the ever-greater use of premises out of normal school hours, as well as a refurbishment backlog.

At present, only a few communities are developing integreated cifty wide eoncepts for school location planning that address these challenges by taking account of both social and spatial considerations as well as policy issues relating to real estate and health care. There is an immense need for adequate responses in these areas. Also, decisions on school building extensions and site closures need to be carefully explained to both the local community and the school users in order for them to be accepted and endorsed.

\section{DIFFERING VIEWS, ROLES AND RESPONSIBILITIES}

Because the challenges are multifaceted, each comprehensive project - be it an extension, renovation or new construction - needs to be prepared carefully; dialogue should be engaged with the users so that their various needs are understood. The process of planning a school brings together people who have different cultural values and norms. Their perception of things, their expectations and fields of expertise all differ.

When a complex school building programme is launched for the first time, it often arouses questions and apprehension within the community. After all, teachers are not construction experts, nor are architects teachers. Who is really familiar with terms such as "early interaction", "blind arch", "open learning" or "mixed-age cluster"? If partners are to engage in a healthy dialogue, everyone involved should ensure that ideas are communicated in a clear and understandable manner. Actors should articulate their goals clearly and make an effort to understand each other.

It is important to bring together all the actors involved in the process of building or refurbishing a school as early as possible. They need to voice their aspirations, but also their concerns. Otherwise, steps taken in relation to costs, time efficiency, usability and design may not be in tune.

The drawings and comments that follow offer insights into understanding who participates in these processes. Only the primary partners are portrayed; other crucial actors such as politicians, parents or the local community would normally complete the picture.

At the outset of many construction and refurbishment processes, some actors fear being overruled. This feeling may increase if partners set themselves apart from others by using technical language, claim that certain measures are mandatory (for example, fire safety systems); they may even have personal interests. A sound participatory process can only take place if there is a balanced partnership between all actors. It needs to be built on dialogue during which other partners' points of view are treated with respect. It is also helpful to have a neutral moderator and a clear division of responsibilities. Co-ordination can be facilitated by an interdisciplinary steering group within the school or a main point of contact within the local authority. 


\section{Standards}

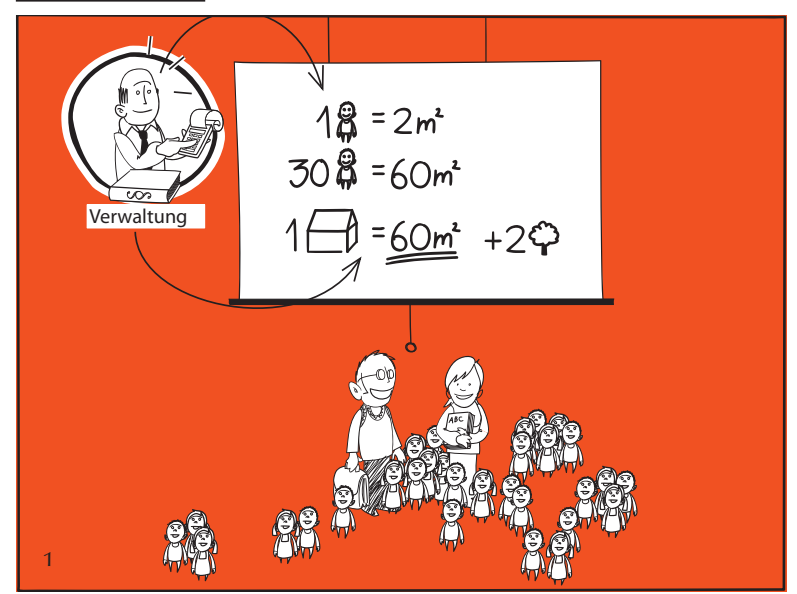

Drawing: Maxvon Bock, Berlin

\section{Builder/local authority}

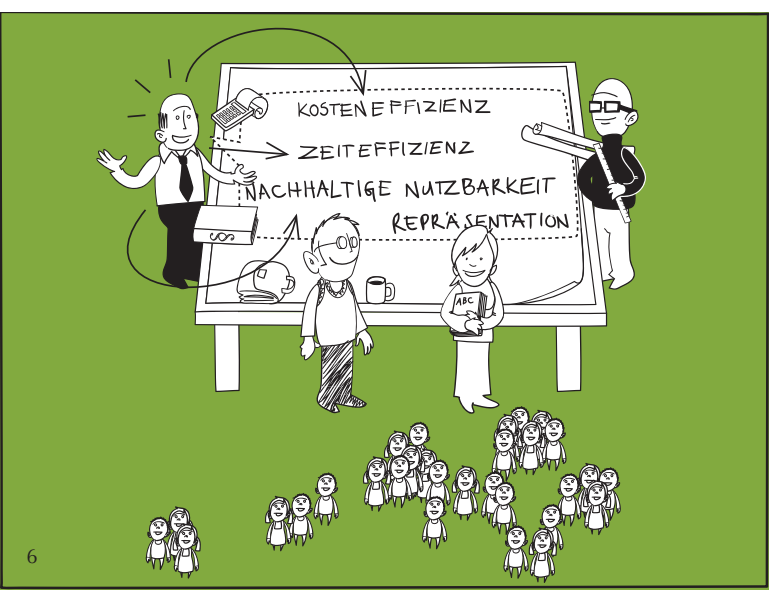

Drawing: Max von Bock, Berlin

\section{Users}

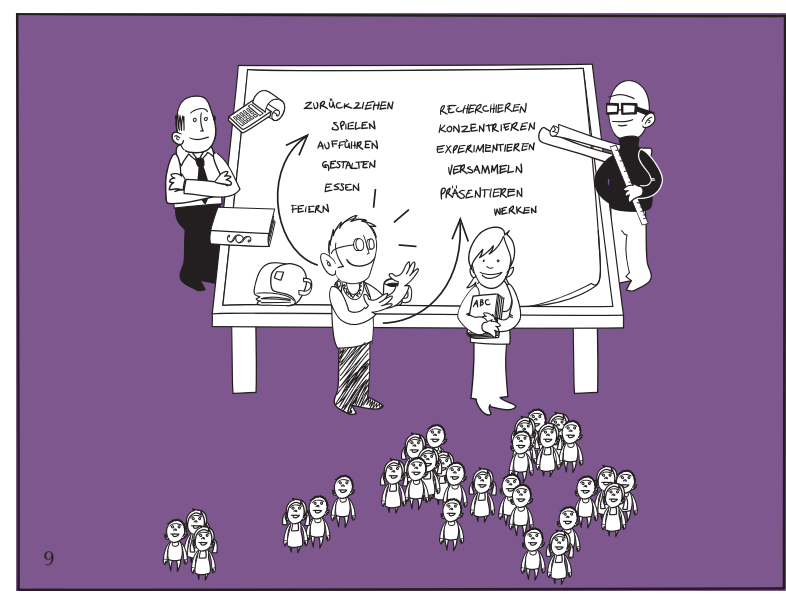

Drawing: Maxvon Bock, Berlin

\section{Figure 1}

A standardised school design. The per-capita floor area is defined, but there is no indication of quality.

In most German-speaking countries, school design is highly standardised. Generally, quantities, uses and minimum standards are defined in standards and guidelines. However, often the quality of interior equipment and finishings is not specified. Nor do guidelines systematically describe processes or propose modes for decision making.

\section{Figure 2}

The building authorities specify the criteria the builder must respect, i.e. cost efficiency, time efficiency and sustainability; they want the result to be prestigious.

The (public-sector) builder applies the principles of cost efficiency and democratic transparency and conforms to local policy. Tailor-made solutions are often rejected because they entail greater costs, while a high degree of user participation is seen as a threat to timely project completion. Lastly, the local authority is often understaffed and cannot realistically monitor several projects in parallel.

\section{Figure 3}

Teachers (preferably together with their pupils) describe the activities they want to use the building for: this can range from focused learning to leisure. They do not decide on the number and size of rooms.

Participating in a planning process is something that, usually, users are confronted with very rarely. They are therefore incapable of analysing floor plans or calculating building costs. Their role is to describe their expectations of a school based on their own experience, and not to try to be architects. Interestingly enough, teachers often tend to refer to the school they are familiar with as a model for future schools. 


\section{The architect/designer}

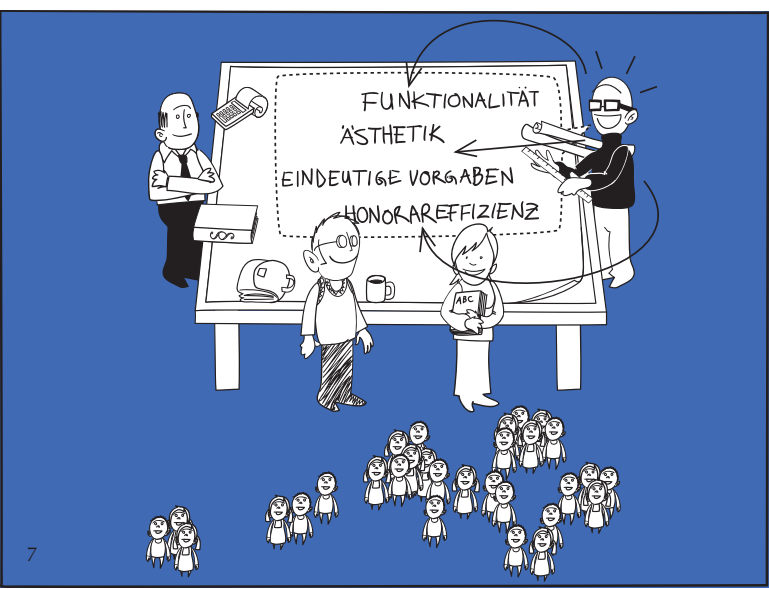

Drawing: Max von Bock, Berlin

\section{Figure 4}

The architect focuses on the aspects that are important for him/her: functionality, aesthetic appeal, clear guidelines from the builder and satisfactory financial compensation.

The (private sector) architect/designer wants to design a building that is aesthetic and functional. He is not a pedagogue and therefore tends to draw from his own school experience. This is why (s)he needs clear input from users. The architect is often expected to align the builder's constraints with those of the users. In general, it is better to assign this task to moderators, who are neutral.

\section{USERS' NEEDS FORM THE CRUX OF THE PLANNING PROCESS}

Before a comprehensive refurbishment programme is launched - i.e. during phase one - the school has to identify its needs and requirements. The general framework defined by the existing architecture (such as the site and building itself) and the builder's constraints (i.e. time frame and construction costs) have to be detailed.

It is at this point that all needs and aspirations are drawn up for the first time. The broad lines of the ongoing process are set: it will be determined if, for example, same-age groups will work together, if there will be study areas to allow for individual learning, or whether teachers will be allocated appropriate amounts of space to prepare for their classes, etc.

In relation to spatial design, here are some of the most important questions that have to be answered:

- On what sort of learning culture will the school be based?

- How will individual learning, learning in groups and shared instruction relate to each other?

- Should classes be organised in clusters to allow for team-oriented activities or learning in mixed-age groups?

- How does the school position itself in relation to the surrounding urban community? To what extent should it open its doors to others, and when should it not? Do other institutions dispensing formal/ informal learning have partnerships with the school? Is multiple use foreseen to cater for their needs?

- Last but not least, what is the teachers' daily role? How much space do they dispose of to work, plan, counsel students and confer with others?

These questions should be addressed in the presence of moderators and take into account the issues raised by the school community at large. The process should include the pupils and their parents, as well as the technical staff who are normally familiar with the building. It is worth establishing an informal board that has a say in the whole process - from the initial ideas and design concept to furnishings and equipment. 
The results of these processes are not usually available at the outset of a project. Schools and building authorities need to feed them back into the ongoing process and constantly adjust them according to the site's specificities. Spatial demands should not be expressed in square metres, because this will result in territorial conflicts. It is much better to describe them in terms of activities and functionalities.

By the time these points have been worked out it still takes a lot of time before a school is actually built. But when needs and demands are predefined, all options have been explored and the school's objectives have been identified, the project will get off to a good start. A successful process therefore depends upon a virtual but predefined spatial design programme that can be adjusted to local conditions in different settings. According to European standards, this should constitute the first step in the development of a draft design. It should then be developed in conjunction with users and builders. This way, all stakeholders' voices are heard.

For more information, contact:

Frauke Burgdorff, Dipl.-Ing. Raumplanung

Director

Montag Stiftung Urbane Räume gAG

Adenauerallee 127

D 53113 Bonn

Germany

E-mail: f.burgdorff@montag-stiftungen.de

Dr. Karl-Heinz Imhäuser

Director

Montag Stiftung Youth and Society

Adenauerallee 127

D 53113 Bonn

Germany

E-mail:kh.imhaeuser@montag-stiftungen.de 


\section{ORGANISATION FOR ECONOMIC CO-OPERATION AND DEVELOPMENT}

The OECD is a unique forum where governments work together to address the economic, social and environmental challenges of globalisation. The OECD is also at the forefront of efforts to understand and to help governments respond to new developments and concerns, such as corporate governance, the information economy and the challenges of an ageing population. The Organisation provides a setting where governments can compare policy experiences, seek answers to common problems, identify good practice and work to co-ordinate domestic and international policies.

The OECD member countries are: Australia, Austria, Belgium, Canada, Chile, the Czech Republic, Denmark, Estonia, Finland, France, Germany, Greece, Hungary, Iceland, Ireland, Israel, Italy, Japan, Korea, Luxembourg, Mexico, the Netherlands, New Zealand, Norway, Poland, Portugal, the Slovak Republic, Slovenia, Spain, Sweden, Switzerland, Turkey, the United Kingdom and the United States. The European Commission takes part in the work of the OECD.

OECD Publishing disseminates widely the results of the Organisation's statistics gathering and research on economic, social and environmental issues, as well as the conventions, guidelines and standards agreed by its members.

This work is published on the responsibility of the Secretary-General of the OECD. The opinions expressed and arguments employed herein do not necessarily reflect the official views of the Organisation or of the governments of its member countries.

You can copy, download or print OECD content for your own use, and you can include excerpts from OECD publications, databases and multimedia products in your own documents, presentations, blogs, websites and teaching materials, provided that suitable acknowledgment of OECD as source and copyright owner is given. All requests for public or commercial use and translation rights should be submitted to rights@oecd.org. Requests for permission to photocopy portions of this material for public or commercial use shall be addressed directly to the Copyright Clearance Center (CCC) at info@copyright.com or the Centre français d'exploitation du droit de copie (CFC) at contact@cfcopies.com. 